\title{
EDITORIAL
}

\section{Australian Dreamtime}

In an Editorial in 1992 I wrote of the value of International Congresses of Nutrition as a way of getting a wider view of the state of the Nutritional Sciences. I have just returned from the Congress in Adelaide and it seemed appropriate to use the first Editorial of 1994 to give a personal view of the state of nutrition as seen from the viewpoint of a participant at that Congress. I was fortunate in that $\mathbf{I}$ attended a satellite meeting in Sydney a week before the Congress because the combined effects of a journey with a total elapsed time of twenty-nine hours, coupled with the inversion of night and day that the trip to Australia involves, made the early part of the meetings rather like a dream: a feeling that was enhanced by the Aboriginal dancers at the opening ceremony of the Congress. The first impression was that the programme reinforced my views on the many aspects of science that fall within the boundary of the Nutritional Sciences. Quite clearly, Nutrition is 'the meeting place of many disciplines' focused on the study of the effects of food on the organism.

Organizing the schedules of an International Congress is, to put it mildly, a nightmare because of the many interests that cry out to be included. The typical participant with a range of interests needed a very sophisticated time-planning program to work out the best options for using his or her time. In fact, as far as I was concerned the decision was, at times, impossible to make on grounds of logic or personal interest and I decided to go to sessions where I felt I would be educated about a growth-point with which I was unfamiliar. I also spent a great deal of time looking at the posters on the premise that one could reasonably expect some of them to be embryonic papers that would eventually come across my desk at the British Journal of Nutrition.

Some plenary lectures covered some familiar themes and I again felt that I was dreaming and had been taken back to previous International Congresses where the same problems had been debated and the same calls for action made, and I wondered what we as nutritionists had been doing wrong, or not doing, that our messages had not got through.

Other major presentations still had the capacity to inspire and make one feel that, in addition to the intrinsic scientific interest, nutritional studies still had something to contribute to human well-being and to satisfying the altruistic motivation that many nutritionists have.

Some new themes were more evident at this Congress. First there was the Congress theme which explored the need for the food supply to be linked with sustaining the environment and the session on the implications of climatic change for food production linked well with this theme. Nutrition education also had a higher profile, largely I suppose because many countries are developing food and nutrition policies and recognize the need to monitor their effectiveness. Food choice and the behavioural issues involved in the selection of the diet also were clearly in evidence in symposia and poster presentations.

All the more conventional areas were represented: energy metabolism, nutrient requirements, the assessment of nutritional status, effects on growth development and lactation, for example, together with considerable discussion on the central role of women in many cultures as the key element in the production of food and in controlling the nutritional status of the family.

One interesting element of the Congress which gave it a distinctive Australian flavour was the growing interest in the diets of indigenous peoples, with particular reference to the Aborigines and the peoples of the South-Pacific region. This was particularly interesting to 
me because of the range of foods consumed, the 'bush tucker', and because of the lessons that can be learnt from the study of hunter-gatherers. This linked very nicely back to the theme of a sustainable food supply and the preservation of the environment with which the Aborigines seem to have some mystical union.

There was of course lots of good hard science as well; the applications of molecular biological techniques and concepts to understanding the interactions between the diet and the individual are beginning to bear fruit, although I think both nutritionists and molecular biologists will have to work together at breaking down the barriers that could be produced by the rapidly evolving special language of the molecular biologists, a concern that we at the Journal have in making molecular biological papers, as they say, accessible to nutritional readers of the Journal. It seems quite clear that there are interactions between the genetic makeup of individuals and the components of the diet that may act in two senses, and we had a good account of the way that nutrient intake may alter gene expression and where the genetic susceptibility to disease accounts for some of the nutritional individuality that confounds many of our studies on the relationship between diet and disease.

I was struck by the unevenness in the standards of presentation; it is surprising that experienced presenters persist in using slides that convey little to their audience, either because they are too detailed or because they follow the trend to adopt the style of the adman in having coloured backgrounds of varying density that reduce the contrast on the slide and obscure the content. In a programme where there was very little time to spare it was also very annoying to find speakers overrunning and effectively frustrating the efforts of the organizers to allow participants to move from one session to another to follow their specific interests.

The poster presentations also showed an extreme range of styles, from the glossy professional poster to the typewritten account and in one case a hand-written one. The two books of abstracts gave only a hint of what some authors were going to present and many authors discounted the fact that with so many posters to see the abstract was the essential 'bait' to get their posters visited. Many authors of papers also fail to recognize the importance of abstracts and synopses, often seeing their preparation as a chore, only undertaken to satisfy an editor, whereas they are in fact an important part of a paper, the 'headline' that catches the reader's eye, and one that therefore needs to be specially interesting and informative.

One of the strongest messages that I took away from the Congress was that the Nutritional Sciences, if they are to advance and make their proper contribution to human well-being and the advancement of knowledge, must present more strongly the intellectual challenge that these applied studies demand. The issues that need to be resolved are of great complexity and demand the application of the most sophisticated techniques, ranging from those of the molecular biologist to the behavioural scientist. And above all we must be aware of the need to convey these truths about the nature of our science to the administrators, both scientific and political.

In this respect it was encouraging to hear the Federal Minister for Health, when opening the Satellite meeting in Sydney, showing a clear recognition of the need for basic nutritional information as a prerequisite for $\mathrm{a}$ food and health policy and the recognition that nutrition education and improved communication were the key to implementing dietary change.

The International Congress in Adelaide was, I believe, an excellent example of how to improve communication between nutritional scientists and, I hope, for encouraging them to convey the current developments to their colleagues who could not attend. In this I am sure that the informal meetings between sessions and during the social programmes will prove to be as productive as the well-organized formal programme. 